\title{
Earthquakes and Multi-hazards around the Pacific Rim, Vol. 1: Introduction
}

\section{Yong-Xian Zhang, ${ }^{1}$ Thomas Goebel, ${ }^{2}$ Zhigang Peng, ${ }^{3}$ Charles Williams, ${ }^{4}$ Mark Yoder, ${ }^{5}$ and John Rundle ${ }^{5}$}

The seismic belt along the Pacific Rim is the greatest earthquake zone in the world, generating more than $80 \%$ of the world's largest earthquakes (https:// earthquake.usgs.gov/learn/topics/megaqk_facts_fanta sy.php). It is also susceptible to tsunamis and volcanic eruptions, which could generate serious multihazards. Since the beginning of the twenty-first century, most countries along the Pacific Rim have suffered from tremendous multi-hazards, especially earthquakes and tsunamis. For example, the 2004 Sumatra M9.1 earthquake in Indonesia and the 2011 Tohoku M9.0 earthquake in Japan triggered megatsunami and caused significant damages and human casualties. An improved understanding of the underlying physical processes and potential interactions of these multi-hazards, and better simulation and forecasting of their occurrences are needed for better disaster prevention/mitigation.

The APEC Cooperation for Earthquake Simulation (ACES) (http://www.aces.org.au/), endorsed by APEC (Asia-Pacific Economic Cooperation) in 1997, has been focusing on understanding, forecasting, and mitigating the effects of earthquakes and other natural disasters for about 20 years. It links the complementary strengths of the earthquake research programs of individual APEC member economies via collaborations toward the development of earthquake

\footnotetext{
1 China Earthquake Networks Center, Beijing 100045, China. E-mail: yxzhseis@sina.com

2 Seismological Laboratory, Earth and Planetary Sciences, University of California, Santa Cruz, Santa Cruz, CA 95064, USA. E-mail: tgoebel@ucsc.edu

3 Georgia Institute of Technology, Atlanta, GA 30332, USA. E-mail: zpeng@gatech.edu

4 GNS Science, Lower Hutt 5040, New Zealand. E-mail: c.williams@gns.cri.nz

5 Department of Physics, UC Davis, Davis, CA 95616, USA. E-mail: mryoder@ucdavis.edu; jbrundle@ucdavis.edu
}

simulation models and creates the research infrastructure to enable large-scale simulations and to assimilate data into the models. Since 1997, twelve workshops, including nine international workshops and three working group meetings on earthquake simulations (http://www.aces.org.au/), have been held by ACES: (1) Inaugural ACES Workshop, January 31-February 5, 1999, Brisbane and Noosa, Queensland, Australia; (2) 2nd ACES Workshop, October 15-20, 2000, Tokyo and Hakone, Japan; (3) 2nd ACES Working Group Meeting, July 29-August 3, 2001, Maui Supercomputer Center, USA; (4) 3rd ACES Workshop, May 5-10, 2002, Maui, Hawaii, USA; (5) 3rd ACES Working Group Meeting, June 2-6, 2003, Melbourne and Brisbane, Australia; (6) 4th ACES Workshop and iSERVO colloquium July 9-14, 2004, Beijing, China; (7) 5th ACES International Workshop April 4-6, 2006, Hawaii, USA; (8) 6th ACES International Workshop May 11-16, 2008, Cairns, Australia; (9) 7th ACES International Workshop October 3-8, 2010, Hokkaido, Japan; (10) ACES Workshop on Advances in Simulation of Multihazards, Maui, Hawaii, May 1-5, 2011; (11) 8th ACES International Workshop on Advances in Simulation of Multihazards, Maui, Hawaii, October 23-26, 2012; (12) 9th ACES International Workshop on Advances in Simulation of Multihazards, Chengdu, China, August 10-16, 2015. As a result of ACES, much progress has been achieved on Lattice Solid particle simulation Model (LSM), Australian Computational Earth Systems Simulation (ACcESS), Earth Simulator of Japan, Geotechnical Finite Element Analysis (GeoFEM), Geophysical Finite Element Simulation Tool (GeoFEST), Earthquake Simulator (QuakeSIM), Solid Earth Virtual Research Observatory Institute (SERVO), International Solid Earth Virtual Research Observatory Institute (iSERVO), Load-Unload Response Ratio (LURR), 
Pattern Informatics (PI), Critical Sensitivity, Earthquake Critical Point Hypothesis, the Virtual California model (VC), Relative Operating Characteristic (ROC), Multiscale Finite-Element Model (MFEM), the Uniform California Earthquake Rupture Forecast (UCERF), etc. In the late 2000s, multihazards became a theme of ACES, and the ACES Workshop on Advances in Simulation of Multihazards was held in Maui, Hawaii, May 1-5, 2011, soon after the Tohoku M9.0 earthquake and tsunami.

Special Issues have been published after each ACES workshop, with themes related to the themes of the workshop (Donnellan et al. 2004, 2015; Fukuyama et al. 2013; Matsu'ura et al. 2002; Mora et al. 2000; Yin et al. 2006). This special issue, named 'earthquakes and multi-hazards around the Pacific Rim,' contains many of the results presented at the 9th ACES International Workshop on Advances in Simulation of Multihazards, Chengdu, China, August 10-16, 2015 (http://www.csi.ac.cn/ ACES2015/Home/index.html), as well as additional related topics.

The 9th workshop included seven regular sessions (microscopic simulation; scaling physics; macroscale simulation: earthquake generation and cycles; macroscale simulation: dynamic rupture and wave propagation; computational environment and algorithms; data assimilation and understanding; model applications) and four special sessions. The special sessions were highlighted by 'Global Navigation Satellite System (GNSS) Tsunami Early Warning System: Models, Simulations, Data and Technology.' The research results of the April 24, 2015, Magnitude 7.8 Lamjung (Kathmandu), Nepal Earthquake were also discussed in a special session. The other two special sessions were 'Earthquake simulation and forecasting in China: State-of-the-art and future prospective,' and 'The lure of LURR - Celebration of Professor Yin's 80th Birthday.'

This topical issue is divided into two volumes. The first volume (Vol. I) includes 16 papers, which are further divided into three sections. Papers on earthquake physics are presented first, followed by papers on earthquake simulation and data assimilation. The final section covers multi-hazard assessment and earthquake forecasting models.
In the first section, S. W. Hao et al. present experimental results that examine the evolution properties of rocks during the secondary, nearly constant strain rate stage of deformation. Their experiments indicate that a lower ratio in the slope of the secondary stage with respect to the average rate of the entire lifetime implies more brittle failure modes. Y. Urata et al. examine the influence of loading velocity, cumulative slip and gouge on constitutive parameters within a rate-and-state friction law, using experiments and a spring-slider model. The authors find that conventional rate-and-state formulations cannot capture the observed evolution of frictional parameters with cumulative slip. R. R. Castro et al. determine source parameters and quality factors for an earthquake sequence that occurred in the Gulf of California in October 2013. They resolve a mainshock stress drop of $1.7 \mathrm{MPa}$ and the frequency dependence of seismic wave attenuation. In order to study the stress distribution near the seismic gap between the M8.0 Wenchuan and M7.0 Lushan Earthquakes, Y. H. Yang et al. determine the focal mechanisms of 228 earthquakes with magnitude $M \geq 3$ from January 2008 to July 2014 near the seismic gap along the Longmenshan Fault Belt by using a full waveform inversion method and then apply a damped linear inversion method to derive the regional stress field based on the determined source parameters. Their results suggest that from west to east across the three main imbricated faults of the Longmenshan fault system, the faulting types change from thrust in the westernmost region to strike-slip in the central part and to normal and mixed faulting at the east end.

In the second section, K. W. Schultz et al. (2017) introduce a new slip-weakening friction law used in the Virtual Quake Simulator. They explore the effects of the frictional law parameters on seismicity rate simulations with the UCERF3 California fault model. They find that the new model extends the magnitude ranges where earthquake rates from simulations match observations in California, and improves the agreement between the simulated and observed scaling relations. M. Wilson et al. develop a statistical method to evaluate earthquake simulators based on observed seismicity data. J. Parker et al. discuss automated methods to locate and measure surface 
fault slip using deformation measurements from the NASA Uninhabited Aerial Vehicle Synthetic Aperture Radar (UAVSAR) data. UAVSAR is similar to satellite-based SAR, but can facilitate higher mission flexibility and superior pixel resolution, of approximately $7 \mathrm{~m}$. The presented methods use freely available data products from the UAVSAR mission. T. H. W. Goebel et al. examine the variability of seismic stress drops, looking specifically at the San Gorgonio Pass and Ventura Basin in southern California. They improve the resolution of their method by stacking large numbers of source spectra. They find that events in the Ventura Basin (high loading rates) have lower stress drops than those in the San Gorgonio Pass (slow loading rates). Y. Y. Kropivnitskaya et al. analyze anthropogenic data from social media sources like Twitter in combination with contemporary physical sensor data, to estimate local earthquake intensity. Their algorithm and results show that combining social media-based metrics with data from physical type sensors produces intensity maps with more complete coverage, improved accuracy, and higher resolution than maps using either data source separately.

In the third section, H. W. Li et al. conduct a probabilistic tsunami hazard assessment in the South China Sea and neighboring basins. They perform a thorough review of historic earthquake and tsunami events followed by evaluations of the upper and lower bounds of tsunami hazard based on different corner magnitudes. They suggest that multi-disciplinary studies with seismic, geodetic, tectonic, and tsunami generation are needed to improve tsunami hazard evaluation in this region. $\mathrm{Z}$. L. Wu et al. summarize the approach in China since the last 1.5 decade of using apparent stress for time-dependent seismic hazard assessment or earthquake forecasting. The research results show that this approach, seemingly uniquely carried out on a large scale in mainland China, provides the earthquake catalogues for the predictive analysis of seismicity with an additional degree of freedom, deserving a systematic review and reflection. H. Z. Yu et al. use a combination of spatial and temporal earthquake forecast methods and suggest that using this ensemble of methods may help improve short to intermediate term forecasts. S. F. Zhang et al. investigate methods to determine false alarm rates in annual earthquake forecasts for China and suggest a method to reduce such false alarms. Y. X. Zhang et al. present and validate an earthquake forecast, based on the Pattern Informatics (PI) method, of the Tibetan Plateau region during the time period 2008-2014, including the 2008 M8.0 Wenchuan earthquake. The forecast is verified using a receiver operating characteristic (ROC) metric and $R$ score. They show that the PI metric significantly outperforms a random forecast and that some models with a larger grid and longer time window have higher forecasting efficacy. K. Katsumata analyzes earthquake catalogues provided by the International Seismological Center (ISC) to detect earthquake quiescence in and near Japan by using a simple scanning technique (ZMAP). They decluster earthquake swarms and aftershocks by a stochastic de-clustering method based on the Epidemic-Type Aftershock Sequence model (ETAS). Their results show that 11 significant quiescences of more than 9 years occurred during 1964-2012, and 3 of them were followed by $M_{\mathrm{w}} \geq 8.25$ earthquakes, while there were $4 M_{\mathrm{w}} \geq 8.25$ earthquakes during this time period. A. Hawkins et al. examine the statistics of induced and triggered seismicity at the Geysers geothermal field in California. Their results support the idea that these earthquakes are caused by a reduction in friction on the associated faults as a result of injected fluid. They also find that the induced seismicity obeys Gutenberg-Richter (GR) scaling, and that aftershocks of the induced earthquakes obey GR scaling as well.

We thank the contributors to this and previous topical volumes, especially the authors, reviewers, Birkhauser personnel to make this topical volume happen. We would like to thank Dr. Renata Dmowska, the Editor-in-Chief, for Topical Issues of PAGEOPH, for her support and patience during the editing process. Special thanks to Prof. X. C. Yin's contribution to ACES for nearly 20 years. Finally, we would like to acknowledge our sponsors of the 9th ACES workshop, the China Earthquake Administration, the Ministry of Science and Technology, and the Ministry of Finance of the People's Republic of China. The China Earthquake Networks Center hosted the ACES workshop together with the Institute of Earthquake Science, the China Earthquake 
Administration, the Sichuan Earthquake Administration, the Computer Network Information Center, the Chinese Academy of Sciences, and the State Key Laboratory of Nonlinear Mechanics, Institute of Mechanics, Chinese Academy of Sciences.

\section{REFERENCES}

Donnellan, A., Mora, P., Matsu'ura M. \& Yin, X.-C. (Eds.). (2004). Computational earthquake science, part I and II. Pure and Applied Geophysics, 161 (9/10 \& 11/12), (Birkhauser, 2004).

Donnellan, A., Williams, C. \& Pierce, M. (2015). Multihazard simulation and cyberinfrastructure. Pure and Applied Geophysics, 172(8), 2083-2085. doi:10.1007/s00024-015-1074-1.
Fukuyama, E., Rundle, J.B. \& Tiampo, K.F. (Eds.) (2013), Earthquake hazard evaluation. Pure and Applied Geophysics, 170 (1/ 2), 560 pp. (Springer, Basel, 2013).

Matsu'ura, M., Mora, P., Donnellan, A. \& Yin, X-C. (Eds.) (2002), Earthquake processes: physical modelling, numerical simulation, and data analysis, part I and II. Pure and Applied Geophysics, 159(9/10), (Birkhauser, 2002).

Mora, P., Matsu'ura, M., Madariaga, R. \& Minster, J-B. (Eds.) (2000), Microscopic and macroscopic simulation: towards predictive modelling of the earthquake process. Pure and Applied Geophysics, 157 (11/12), (Birkhauser Verlag, 2001).

Yin, X.-C., Mora. P., Donnellan, A. \& Matsu'ura, M. (Eds.). (2006). Computational earthquake physics: simulations, analysis and infrastructure, part I and II. Pure and Applied Geophysics, 163(9 \& 11-12) (Birkhauser, 2006 and 2007). 